\title{
Relationship Between Changes in Serum Levels of Intact Parathyroid Hormone and Sclerostin After a Single Dose of Zoledronic Acid: Results of a Phase 1 Pharmacokinetic Study
}

\author{
Tatsuhiko Kuroda ${ }^{1}$ - Masataka Shiraki ${ }^{2}$ (D) Toshitaka Nakamura $^{3} \cdot$ Hiroaki Suzuki $^{4}\left(\right.$ Kazuki Hiraishi $^{4}(\mathbb{D} \cdot$ \\ Toshitsugu Sugimoto $^{5}$ (D) Satoshi Tanaka ${ }^{6}$ (i)
}

Received: 22 April 2021 / Accepted: 30 July 2021 / Published online: 24 August 2021

(c) The Author(s) 2021

\begin{abstract}
Although changes in serum sclerostin levels at 12 months after infusion of zoledronic acid have been reported, the changes in sclerostin levels at earlier time points are poorly understood. We reanalyzed the study data of a previous phase 1 pharmacokinetic study and investigated the correlation between changes in sclerostin levels and relevant factors in calcium metabolism. A total of 24 Japanese female subjects with primary postmenopausal osteoporosis were administered a single 4- or 5-mg dose of zoledronic acid. Serum and urine samples were collected on days 15, 29, 90, 180, and 365 after administration. Serum levels of calcium, phosphate, intact parathyroid hormone (iPTH), and sclerostin were measured. Levels of serum sclerostin were unchanged from baseline on days 15 and 29, but increased significantly on day 90, subsequently decreased significantly on day 180, and returned to baseline levels on day 365. A significant negative correlation was observed between changes in iPTH levels at early time points and sclerostin levels at later time points. This suggests that sclerostin was negatively regulated by $\mathrm{PTH}$, and the decrease in sclerostin may indicate the start of bone formation during later time points after zoledronic acid injection.
\end{abstract}

Keywords Zoledronic acid $\cdot$ Sclerostin $\cdot$ Parathyroid hormone $\cdot$ Bone formation

Satoshi Tanaka

tanaka.sj@om.asahi-kasei.co.jp

1 Healthcare R\&D Center, Asahi Kasei Corporation, 1-1-2 Yurakucho, Chiyoda-ku, Tokyo 100-0006, Japan

2 Research Institute and Practice for Involutional Diseases, 1610-1 Meisei, Misato, Azumino, Nagano 399-8101, Japan

3 Touto Sangenjaya Rehabilitation Hospital, 1-24-3 Sangenjaya, Setagaya-ku, Tokyo 154-0024, Japan

4 Medical Affairs Department, Asahi Kasei Pharma Corporation, 1-1-2 Yurakucho, Chiyoda-ku, Tokyo 100-0006, Japan

5 Internal Medicine 1, Faculty of Medicine, Shimane University, 89-1 Enya-cho, Izumo, Shimane 693-8501, Japan

6 Development Planning, Clinical Development Center, Asahi Kasei Pharma Corporation, 1-1-2 Yurakucho, Chiyoda-ku, Tokyo 100-0006, Japan

\section{Introduction}

Zoledronic acid is categorized as a nitrogen-containing bisphosphonate (BP) with an antiosteoclastic effect [1]. Onceyearly injection of zoledronic acid $5 \mathrm{mg}$ has been widely used for the treatment of osteoporosis [2]. Zoledronic acid significantly increases bone mineral density and reduces fracture risk at vertebral and nonvertebral sites [3, 4]. Several studies have shown rapid decreases in bone resorption markers and subsequent decreases in bone formation markers after zoledronic acid infusion as a result of its antiosteoclastic effect $[4,5]$.

Recently, there has been accumulating evidence that osteocyte-derived proteins play a role in the regulation of bone formation [6]. In particular, sclerostin, a product of the SOST gene, has attracted attention, as it negatively regulates Wnt signaling and bone formation [7, 8]. Several clinical trials have demonstrated differences in the expression of sclerostin depending on the agents used in osteoporosis treatment [9-12]. 
Furthermore, several studies have reported changes in serum sclerostin levels following infusion of zoledronic acid [13-16]. Previous studies have shown that sclerostin levels were not significantly changed from baseline at 12 months after zoledronic acid infusion. However, limited data are available on the changes in sclerostin levels prior to the 12-month time point. We therefore aimed to investigate the changes in sclerostin levels over 12 months after infusion of zoledronic acid using more frequent time points.

In this study, we measured serum sclerostin levels and other bone turnover markers at more frequent time points than those used in our previous phase 1 pharmacokinetic (PK) study [17] and performed a subanalysis to investigate the correlation between changes in sclerostin levels and relevant factors in calcium metabolism to determine how zoledronic acid affects bone formation.

\section{Materials and Methods}

\section{Study Subjects and Treatment}

This post hoc analysis was conducted using data from the PK study, which was a single-administration study with a single-blind design [17]. Twenty-four Japanese female subjects (age: 45-79 years) diagnosed as having primary postmenopausal osteoporosis using the criteria for primary osteoporosis of the Japanese Society for Bone and Mineral Research were enrolled [18]. A single 4- or 5-mg dose of zoledronic acid was administered intravenously over a period of at least 15 min. Subjects with a history of BP use within the 2-year period before the study, kidney disease, abnormal serum calcium levels, or history of diabetes mellitus with diabetic complications were excluded.

Serum and urine samples were collected on days 15, 29, 90,180 , and 365 after drug administration. Oral supplemental calcium $(460 \mathrm{mg})$ and vitamin D $(10.0 \mu \mathrm{g})$ were administered daily during the study period.

\section{Measured Parameters}

Serum levels of calcium, phosphate, and intact parathyroid hormone (iPTH) were measured. iPTH was measured using the Elecsys PTH assay (Roche Diagnostics K.K., Tokyo, Japan; inter-assay coefficient of variation: 2.3-2.5\%). Serum levels of sclerostin were evaluated using an enzyme-linked immunosorbent assay (ELISA) kit (SCLEROSTIN; Biomedica Medizinprodukte, GmbH \& Co KG, Vienna, Austria; inter-assay coefficient of variation: $2.5-7.5 \%$ ). All samples were analyzed by Mitsubishi Chemical Medience (Tokyo, Japan).

This study was conducted in compliance with the Declaration of Helsinki and Good Clinical Practice guidelines.
The study protocol was reviewed by the institutional review board of the study centers. Written informed consent was obtained from all subjects before administration of zoledronic acid.

\section{Statistical Analysis}

Measured parameters are summarized as mean \pm standard deviation (SD). Baseline differences in calcium metabolism and sclerostin between the 4- and 5-mg doses were evaluated using analysis of variance (ANOVA). Percent changes from baseline were evaluated using a paired $t$ test. Differences in percent changes between the 4- and 5-mg doses were evaluated by ANOVA. The relationship between calcium metabolism and sclerostin was evaluated using Spearman's correlation method for the whole set of data and excluding outliers. $p$-values $<0.05$ were considered statistically significant.

\section{Results}

Twenty-four subjects were randomized to the zoledronic acid 4-mg $(n=12)$ or 5-mg $(n=12)$ group. No significant differences were observed in baseline characteristics such as age, body mass index, or years after menopause between the groups [17]. The mean \pm SD age in the 4- and 5-mg groups was $66.8 \pm 5.7$ and $66.2 \pm 8.2$ years, respectively. Baseline levels of serum calcium, phosphate, iPTH, and sclerostin are shown in Table 1. There were no significant differences between the 4- and 5-mg groups. Percent changes in serum calcium, phosphate, and iPTH (integrating data from the 4- and 5-mg groups) are shown in Fig. 1a-c.

After administration of zoledronic acid, rapid decreases were observed in serum calcium and phosphate on days 15 and 29 in both groups. At the same time points, serum iPTH increased reciprocally. Levels of serum sclerostin were unchanged from baseline on days 15 and 29; however, they increased significantly on day 90 , subsequently decreased significantly on day 180, and returned to baseline levels on day 365 (Fig. 1d).

Table 1 Baseline characteristics

\begin{tabular}{lccc}
\hline & Zoledronic acid & Zoledronic acid & $p$-value \\
& 4-mg group & 5-mg group & \\
\hline Serum calcium (mg/dL) & $9.1 \pm 0.4$ & $9.2 \pm 0.4$ & 0.642 \\
Serum phosphate (mg/dL) & $3.7 \pm 0.5$ & $3.6 \pm 0.4$ & 0.402 \\
Serum iPTH (pg/mL) & $39.6 \pm 11.6$ & $49.5 \pm 14.0$ & 0.072 \\
Serum sclerostin (pmol/L) & $973.4 \pm 316.5$ & $949.6 \pm 286.4$ & 0.848
\end{tabular}

Data are mean \pm SD

iPTH intact parathyroid hormone, $S D$ standard deviation 
a

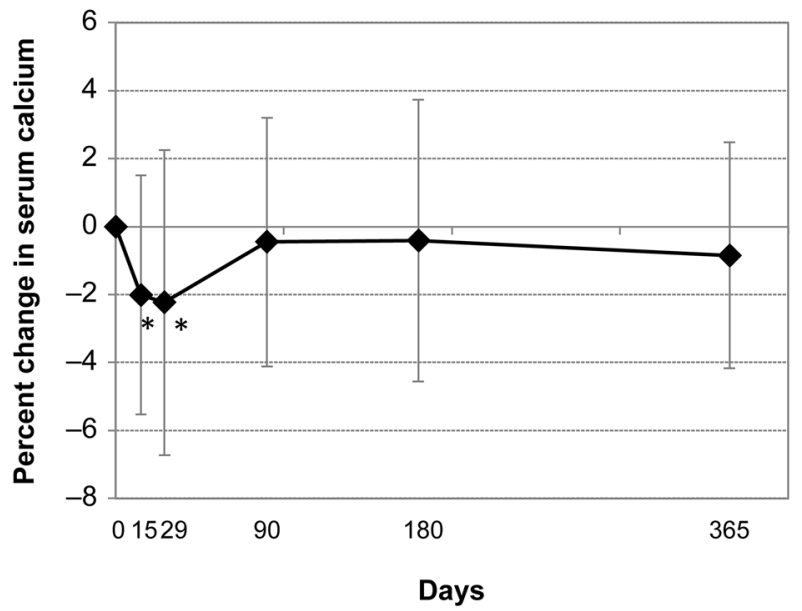

C

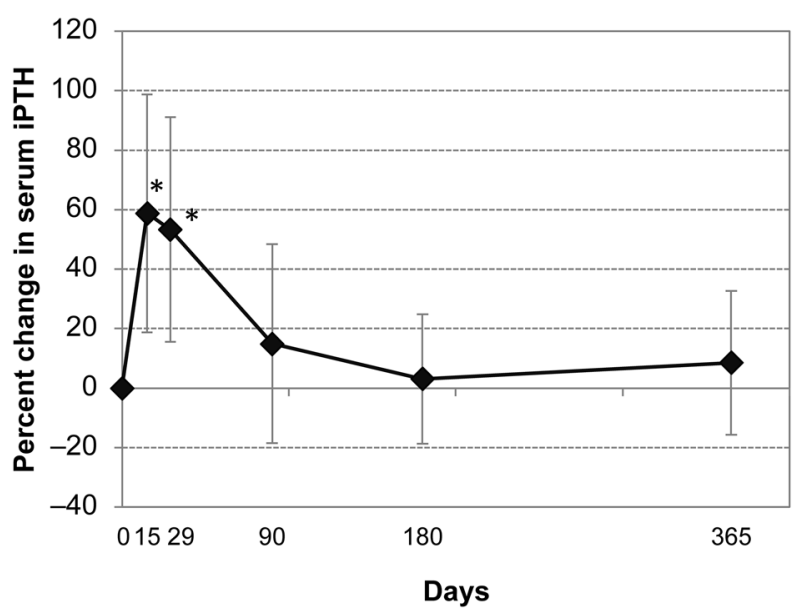

b



d

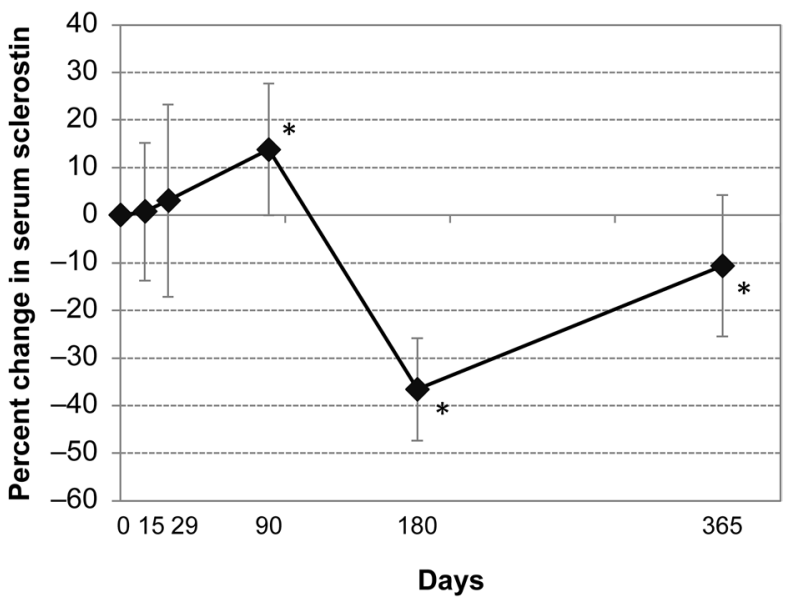

Fig. 1 Time-dependent percent changes in a serum calcium, b serum phosphate, $\mathbf{c}$ serum iPTH, and $\mathbf{d}$ serum sclerostin. Data are mean percent change \pm standard deviation. ${ }^{*} p<0.05$ versus baseline. $i P T H$ intact parathyroid hormone

Correlations between the percent changes in the parameters from baseline to each measurement time point were investigated. Correlations of the changes in levels of calcium as well as phosphate and iPTH at earlier time points are shown in Online Resource 1 using the whole set of data. One outlier each was observed for iPTH at days $0-15$ and days $0-29$. Table 2 summarizes the results of the reanalysis excluding the outliers. The correlations and statistical differences in the parameters were similar between the whole set of data and excluding the outliers. Increases in iPTH on days 15 and 29 were significantly correlated with decreases in serum calcium on day 15 and/or day 29, and the increase in iPTH on day 15 was significantly correlated with a decrease in serum phosphate on day 15 (Table 2).

Online Resource 2 shows the correlations of percent changes in levels of calcium, phosphate, and iPTH at earlier time points (days 15 and 29) with percent changes in levels of serum sclerostin on days 90 and 180 using
Table 2 Correlation of changes in calcium and phosphate with percent changes in iPTH excluding outliers

\begin{tabular}{llllll}
\hline & \multicolumn{2}{l}{ iPTH (days 0-15) } & & \multicolumn{2}{l}{ iPTH (days 0-29) } \\
\cline { 5 - 6 } & $R$ & $p$-value & & $R$ & $p$-value \\
\hline Serum calcium & & & & \\
$\quad$ Days 0-15 & -0.628 & 0.001 & & -0.446 & 0.033 \\
$\quad$ Days 0-29 & -0.358 & 0.093 & & -0.450 & 0.031 \\
Serum phosphate & & & & & \\
$\quad$ Days 0-15 & -0.513 & 0.012 & & -0.128 & 0.560 \\
Days 0-29 & -0.096 & 0.663 & & -0.228 & 0.295 \\
\hline
\end{tabular}

iPTH intact parathyroid hormone

the whole set of data. One outlier each was observed for iPTH at days $0-15$ and days $0-29$. Table 3 summarizes the results of the reanalysis excluding the outliers. The 
Table 3 Correlation of percent changes in $\mathrm{PTTH}$, calcium, and phosphate with percent changes in sclerostin excluding outliers

\begin{tabular}{llllll}
\hline & \multicolumn{2}{l}{$\begin{array}{l}\text { Serum sclerostin } \\
(\text { days 0-90) }\end{array}$} & & \multicolumn{2}{l}{$\begin{array}{l}\text { Serum sclerostin } \\
\text { (days 0-180) }\end{array}$} \\
\cline { 2 - 3 } \cline { 5 - 6 } & $R$ & $p$-value & & $R$ & $p$-value \\
\hline iPTH & & & & & \\
Days 0-15 & -0.075 & 0.733 & & -0.193 & 0.377 \\
Days 0-29 & -0.075 & 0.733 & & -0.431 & 0.040 \\
Serum calcium & & & & \\
Days 0-15 & -0.013 & 0.952 & & 0.260 & 0.220 \\
Days 0-29 & -0.157 & 0.465 & & 0.269 & 0.203 \\
Serum phosphate & & & & 0.045 & 0.834 \\
Days 0-15 & 0.059 & 0.785 & & 0.045 \\
Days 0-29 & -0.039 & 0.856 & 0.318 & 0.130 \\
\hline
\end{tabular}

iPTH intact parathyroid hormone

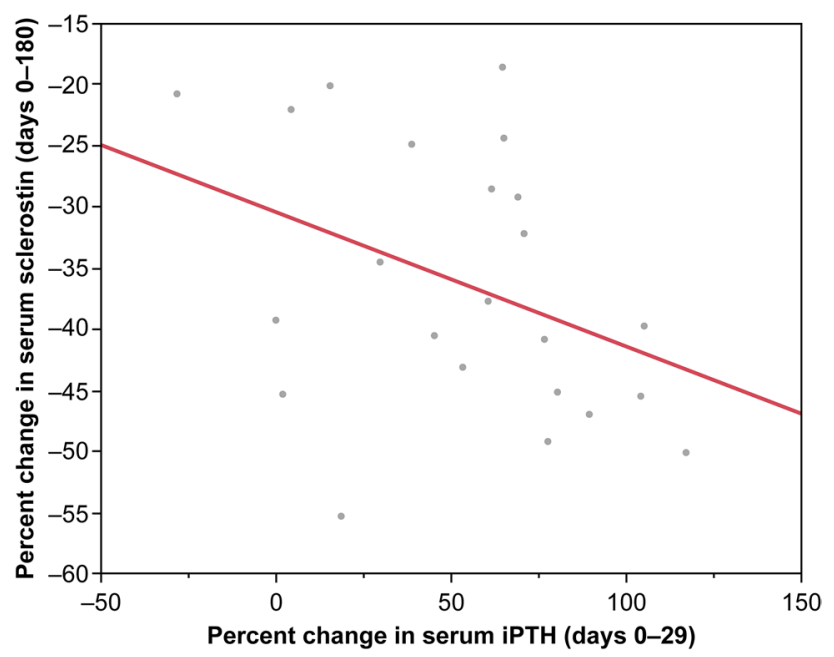

Fig. 2 Correlation between percent change in serum iPTH and sclerostin excluding outliers. $i P T H$ intact parathyroid hormone

correlations and statistical differences in the parameters were similar between the whole set of data and excluding the outliers. Online Resource 3 shows the correlations of percent changes in levels of iPTH at days 0-29 with percent changes in levels of sclerostin at days $0-180$ using the whole set of data. Figure 2 shows the correlation between percent changes in levels of iPTH at days 0-29 and sclerostin at days 0-180 excluding the outliers. Increases in iPTH on day 29 significantly contributed to the subsequent decrease in serum sclerostin (day $180 ; R^{2}=0.186$; Fig. 2). The relationship and trend were similar between the whole set of data and excluding the outliers.

\section{Discussion}

In this analysis, decreases in serum calcium and phosphate were correlated with increases in iPTH at earlier time points after the injection of zoledronic acid. Moreover, increases in iPTH at earlier time points contributed to subsequent decreases in sclerostin.

Changes in sclerostin levels after administration of BPs have been reported previously [12-14, 19, 20]. However, the changes were not significant at 19 months after oral alendronate or risedronate treatment [12]. On the other hand, ibandronate increased the serum level of sclerostin at 1 month and maintained the levels above baseline until 18 months [19, 20]. Several studies have reported on the transition of serum sclerostin levels after administration of zoledronic acid. Catalano et al. reported that serum sclerostin levels peaked on day 7 , with a significant increase observed at 30 days, before returning to baseline beyond 360 days after administration of zoledronic acid [13]. On the other hand, Anastasilakis et al. reported that serum sclerostin levels significantly decreased at 3 months after zoledronic acid administration [14]. These reports indicate that BPs result in sclerostin increases at earlier time points after injection and subsequently result in decreases at later time points.

In the current analysis, we observed significant increases in serum sclerostin on day 90 and subsequent decreases on day 180 after administration of zoledronic acid. The early increase and subsequent decrease in sclerostin was consistent with the findings of other studies, but the timing was delayed. Although this difference may be partly explained by ethnic differences, there are no data measuring sclerostin at the same sampling point for comparison. Zoledronic acid decreases bone resorption by inhibiting osteoclasts at earlier time points, and the reduction in sclerostin at later time points may indicate the start of bone formation.

Correlations between parathyroid hormone (PTH) and changes in sclerostin levels have also been reported. Intermittent PTH has been shown to be associated with a reduction in sclerostin in rodents and in vitro studies [21, 22]. Moreover, serum levels of sclerostin are negatively correlated with the levels of serum PTH in patients with hyperparathyroidism [23]. Drake et al. investigated the change in sclerostin levels with administration of teriparatide $40 \mu \mathrm{g}$ daily; significant decreases in serum sclerostin were observed during the 14-day treatment period [11]. Therefore, changes in endogenous PTH levels or treatment with teriparatide may contribute to changes in sclerostin levels. In our analysis, increases in iPTH at early time points were correlated with decreases in serum sclerostin after intermediate time points, suggesting that BP-related changes in $\mathrm{PPTH}$ may affect decreases in sclerostin. 
It was also reported that another bone resorption inhibitor, denosumab, increased sclerostin levels at 6 months and maintained the levels thereafter [10]. On the other hand, no significant increase in PTH was observed after 3 months of treatment with denosumab [24], suggesting that the relationship between changes in levels of PTH and levels of sclerostin may differ depending on the type of bone resorption inhibitor used for treatment.

This study had several limitations. First, the correlation between iPTH and sclerostin was analyzed using combined data (4- and 5-mg groups), but the changes in serum parameters in each group indicated a similar direction and magnitude. Second, although a correlation between physical activity and serum sclerostin has been reported [25], the level of physical activity was not measured in this study.

In conclusion, once-yearly injection of zoledronic acid initially increased and subsequently decreased serum sclerostin through changes in iPTH levels; a decrease in sclerostin may indicate the start of bone formation during later time points after injection.

Supplementary Information The online version contains supplementary material available at https://doi.org/10.1007/s00223-021-00900-w.

Acknowledgements This study was sponsored and funded by Asahi Kasei Pharma Corporation, Tokyo, Japan. The sponsor had responsibility for quality control. The authors thank the investigators and clinical sites in Japan that participated in this study. Editorial and formatting assistance was provided by Cactus Life Sciences (part of Cactus Communications) and funded by Asahi Kasei Pharma Corporation.

Author Contributions The corresponding author had full access to all of the data in the study and takes responsibility for the decision to submit the article for publication. TK, MS, and ST designed the study. ST is the guarantor. TK analyzed the data. TN, HS, KH, and TS interpreted the data. TK, ST, and HS drafted the manuscript. MS, TN, KH, and TS revised the content of the manuscript. All authors approved the final version of the manuscript and agree to be accountable for the work and to ensure that any questions relating to the accuracy and integrity of the paper are investigated and promptly resolved.

Funding This study was supported by Asahi Kasei Pharma Corporation.

Data Availability Not applicable.

Code Availability Not applicable.

\section{Declarations}

Conflict of interest Tatsuhiko Kuroda is an employee of Asahi Kasei Corporation. Masataka Shiraki has received consulting fees from Asahi Kasei Pharma Corporation, MSD, and Teijin Pharma and lecture fees from Astellas Pharma, Chugai Pharmaceutical, Daiichi Sankyo, Eisai, Eli Lilly Japan, Ono Pharmaceutical, and Pfizer. Toshitaka Nakamura has received consulting fees from Asahi Kasei Pharma Corporation, Amgen, Chugai Pharmaceutical, Daiichi Sankyo, Eli Lilly Japan, MSD, Taisho Toyama Pharmaceutical, and Teijin Pharma. Hiroaki Suzuki, Kazuki Hiraishi, and Satoshi Tanaka are employees of
Asahi Kasei Pharma Corporation. Toshitsugu Sugimoto has received research grants and/or consulting fees from Astellas Pharma, Eisai, Daiichi Sankyo, Chugai Pharmaceutical, and Eli Lilly Japan as well as consulting and/or lecture fees from Asahi Kasei Pharma Corporation and Daiichi Sankyo.

Ethical Approval This study was conducted in compliance with the World Medical Association Declaration of Helsinki Ethical Principles for Medical Research Involving Human Subjects and Good Clinical Practice. The protocol was reviewed by the institutional review board at each study site.

Consent to Participate Written informed consent was obtained from all individual subjects before enrollment in the study.

Consent to Publish All participants gave their written informed consent for the publication of the data in an anonymized form.

Open Access This article is licensed under a Creative Commons Attribution 4.0 International License, which permits use, sharing, adaptation, distribution and reproduction in any medium or format, as long as you give appropriate credit to the original author(s) and the source, provide a link to the Creative Commons licence, and indicate if changes were made. The images or other third party material in this article are included in the article's Creative Commons licence, unless indicated otherwise in a credit line to the material. If material is not included in the article's Creative Commons licence and your intended use is not permitted by statutory regulation or exceeds the permitted use, you will need to obtain permission directly from the copyright holder. To view a copy of this licence, visit http://creativecommons.org/licenses/by/4.0/.

\section{References}

1. Nancollas GH, Tang R, Phipps RJ, Henneman Z, Gulde S, Wu W, Mangood A et al (2006) Novel insights into actions of bisphosphonates on bone: differences in interactions with hydroxyapatite. Bone 38:617-627. https://doi.org/10.1016/j.bone.2005.05.003

2. Boonen S, Black DM, Colón-Emeric CS, Eastell R, Magaziner JS, Eriksen EF, Mesenbrink P et al (2010) Efficacy and safety of a once-yearly intravenous zoledronic acid $5 \mathrm{mg}$ for fracture prevention in elderly postmenopausal women with osteoporosis aged 75 and older. J Am Geriatr Soc 58:292-299. https://doi.org/ 10.1111/j.1532-5415.2009.02673.x

3. Reid IR, Brown JP, Burckhardt P, Horowitz Z, Richardson P, Trechsel U, Widmer A et al (2002) Intravenous zoledronic acid in postmenopausal women with low bone mineral density. N Engl J Med 346:653-661. https://doi.org/10.1056/NEJMoa011807

4. Black DM, Delmas PD, Eastell R, Reid IR, Boonen S, Cauley JA, Cosman F et al (2007) Once-yearly zoledronic acid for treatment of postmenopausal osteoporosis. N Engl J Med 356:1809-1822. https://doi.org/10.1056/NEJMoa067312

5. Nakamura T, Fukunaga M, Nakano T, Kishimoto H, Ito M, Hagino H, Sone T et al (2017) Efficacy and safety of once-yearly zoledronic acid in Japanese patients with primary osteoporosis: two-year results from a randomized placebo-controlled doubleblind study (ZOledroNate treatment in Efficacy to osteoporosis; ZONE study). Osteoporos Int 28:389-398. https://doi.org/10. 1007/s00198-016-3736-y

6. Bellido T (2014) Osteocyte-driven bone remodeling. Calcif Tissue Int 94:25-34. https://doi.org/10.1007/s00223-013-9774-y 
7. Weivoda MM, Youssef SJ, Oursler MJ (2017) Sclerostin expression and functions beyond the osteocyte. Bone 96:45-50. https:// doi.org/10.1016/j.bone.2016.11.024

8. Rossini M, Gatti D, Adami S (2013) Involvement of WNT/ $/$ catenin signaling in the treatment of osteoporosis. Calcif Tissue Int 93:121-132. https://doi.org/10.1007/s00223-013-9749-z

9. Gatti D, Viapiana O, Adami S, Idolazzi L, Fracassi E, Rossini M (2012) Bisphosphonate treatment of postmenopausal osteoporosis is associated with a dose dependent increase in serum sclerostin. Bone 50:739-742. https://doi.org/10.1016/j.bone.2011.11.028

10. Gatti D, Viapiana O, Fracassi E, Idolazzi L, Dartizio C, Povino MR, Adami S et al (2012) Sclerostin and DKK1 in postmenopausal osteoporosis treated with denosumab. J Bone Miner Res 27:2259-2263. https://doi.org/10.1002/jbmr.1681

11. Drake MT, Srinivasan B, Mödder UI, Peterson JM, McCready LK, Riggs BL, Dwyer D et al (2010) Effects of parathyroid hormone treatment on circulating sclerostin levels in postmenopausal women. J Clin Endocrinol Metab 95:5056-5062. https://doi.org/ 10.1210/jc.2010-0720

12. Chung YE, Lee SH, Lee SY, Kim S-Y, Kim H-H, Mirza FS, Lee $\mathrm{S}-\mathrm{K}$ et al (2012) Long-term treatment with raloxifene, but not bisphosphonates, reduces circulating sclerostin levels in postmenopausal women. Osteoporos Int 23:1235-1243. https://doi.org/10. 1007/s00198-011-1675-1

13. Catalano A, Morabito N, Basile G, Brancatelli S, Cucinotta D, Lasco A (2013) Zoledronic acid acutely increases sclerostin serum levels in women with postmenopausal osteoporosis. J Clin Endocrinol Metab 98:1911-1915. https://doi.org/10.1210/jc.2012-4039

14. Anastasilakis AD, Polyzos SA, Gkiomisi A, Bisbinas I, Gerou S, Makras P (2013) Comparative effect of zoledronic acid versus denosumab on serum sclerostin and dickkopf-1 levels of naive postmenopausal women with low bone mass: a randomized, headto-head clinical trial. J Clin Endocrinol Metab 98:3206-3212. https://doi.org/10.1210/jc.2013-1402

15. Gatti D, Viapiana O, Idolazzi L, Fracassi E, Ionescu C, Dartizio C, Troplini S et al (2014) Distinct effect of zoledronate and clodronate on circulating levels of DKK1 and sclerostin in women with postmenopausal osteoporosis. Bone 67:189-192. https://doi. org/10.1016/j.bone.2014.06.037

16. Anastasilakis AD, Polyzos SA, Gkiomisi A, Saridakis ZG, Digkas D, Bisbinas I, Sakellariou GT et al (2015) Denosumab versus zoledronic acid in patients previously treated with zoledronic acid. Osteoporos Int 26:2521-2527. https://doi.org/10.1007/ s00198-015-3174-2

17. Shiraki M, Tanaka S, Suzuki H, Ueda S, Nakamura T (2017) Safety, pharmacokinetics, and changes in bone metabolism associated with zoledronic acid treatment in Japanese patients with primary osteoporosis. J Bone Miner Metab 35:675-684. https://doi.org/10.1007/s00774-016-0806-3

18. Orimo H, Hayashi Y, Fukunaga M, Sone T, Fujiwara S, Shiraki M, Kushida K et al (2001) Diagnostic criteria for primary osteoporosis: year 2000 revision. J Bone Miner Metab 19:331-337. https:// doi.org/10.1007/s007740170001

19. Muschitz C, Kocijan R, Pahr D, Patsch JM, Amrein K, Misof BM, Kaider A et al (2015) Ibandronate increases sclerostin levels and bone strength in male patients with idiopathic osteoporosis. Calcif Tissue Int 96:477-489. https://doi.org/10.1007/ s00223-015-0003-8

20. Gonnelli S, Caffarelli C, Tanzilli L, Pondrelli C, Lucani B, Franci BM, Nuti R (2014) Effects of intravenous zoledronate and ibandronate on carotid intima-media thickness, lipids and FGF-23 in postmenopausal osteoporotic women. Bone 61:27-32. https://doi. org/10.1016/j.bone.2013.12.017

21. Bellido T, Ali AA, Gubrij I, Plotkin LI, Fu Q, O'Brien CA, Manolagas SC et al (2005) Chronic elevation of parathyroid hormone in mice reduces expression of sclerostin by osteocytes: a novel mechanism for hormonal control of osteoblastogenesis. Endocrinology 146:4577-4583. https://doi.org/10.1210/en.2005-0239

22. Silvestrini G, Ballanti P, Leopizzi M, Sebastiani M, Berni S, Di Vito M, Bonucci E (2007) Effects of intermittent parathyroid hormone (PTH) administration on SOST mRNA and protein in rat bone. J Mol Histol 38:261-269. https://doi.org/10.1007/ s10735-007-9096-3

23. Viapiana O, Fracassi E, Troplini S, Idolazzi L, Rossini M, Adami S, Gatti D (2013) Sclerostin and DKK1 in primary hyperparathyroidism. Calcif Tissue Int 92:324-329. https://doi.org/10.1007/ s00223-012-9665-7

24. Anastasilakis AD, Polyzos SA, Makras P, Gkiomisi A, Sakellariou G, Savvidis M, Papatheodorou A et al (2015) Circulating semaphorin-4D and plexin-B1 levels in postmenopausal women with low bone mass: the 3-month effect of zoledronic acid, denosumab or teriparatide treatment. Expert Opin Ther Targets 19:299-306. https://doi.org/10.1517/14728222.2014.983078

25. Pickering ME, Simon M, Sornay-Rendu E, Chikh K, Carlier MC, Raby AL, Szulc P et al (2017) Serum sclerostin increases after acute physical activity. Calcif Tissue Int 101:170-173. https://doi. org/10.1007/s00223-017-0272-5

Publisher's Note Springer Nature remains neutral with regard to jurisdictional claims in published maps and institutional affiliations. 